\title{
Preventive health care among HIV positive women in a Utah HIV/AIDS clinic: a retrospective cohort study
}

Sara E Simonsen ${ }^{1 *}$, Deanna Kepka ${ }^{2}$, Joan Thompson ${ }^{3}$, Echo $L$ Warner ${ }^{4}$, Maggie Snyder ${ }^{3}$ and Kristen M Ries ${ }^{3}$

\begin{abstract}
Background: Despite evidence that HIV positive women may suffer higher rates of heart disease, diabetes, human papillomavirus infection, and some types of cancer, the provision of preventive health services to HIV positive women is unknown. Preventive health services recommended for such women include breast, colorectal and cervical cancer screening, sexually transmitted infection (STI) testing, vaccinations, and patient counseling on a number of issues including sexual behaviors.
\end{abstract}

Methods: This retrospective cohort study utilized medical record reviews of 192 HIV positive women who were patients at the University of Utah Infectious Diseases Clinic in 2009. Medical records were reviewed for all encounters during 2009 using a standardized data collection form; data were collected on patient demographics and a variety of preventive health services. Chi squared tests were used to assess receipt of preventive health services by demographic factors, and multivariable logistic regression was used to determine predictors of receiving select services.

Results: The most commonly recorded preventive services included blood pressure screening, screening for Hepatitis A and B, Tetanus-Diphtheria-Pertussis vaccination, Pneumococcal pneumonia vaccination, substance abuse screening, and mental health screening. STI testing and safe sex counseling were documented in the medical records of only $37 \%$ and $33.9 \%$ of women, respectively. Documentation of cancer screening was also low, with cervical cancer screening documented for $56.8 \%$ of women, mammography for $65 \%(\mathrm{~N}=26 / 40)$ of women, and colorectal cancer screening for $10 \%(N=4 / 40)$ of women, where indicated. In multivariable models, women with private health insurance were less likely to have documented STI testing (OR 0.20; $95 \% \mathrm{Cl} 0.08$ - 0.52), and, Hispanic women were less likely to have documented safe-sex counseling (OR 0.26; 95\% Cl 0.07 - 0.94).

Conclusions: HIV/AIDS providers should focus on the needs of all women for preventive care services, including those with fewer socio-demographic risk factors (i.e., insured, stable housing etc.). In addition, failure to provide STI testing, cancer screening, or safe sex counseling to all patients represents a missed opportunity for provision of services that are important from both a clinical and public health perspective.

Keywords: HIV/AIDS, Women, Preventive health services, Cancer screening, Safe-sex counseling, Sexually transmitted infection testing

\footnotetext{
* Correspondence: sara.simonsen@utah.edu

${ }^{1}$ Department of Family and Preventive Medicine, Division of Public Health, University of Utah, 375 Chipeta Way, Suite A, Salt Lake City, UT 84108, USA Full list of author information is available at the end of the article
} 


\section{Background}

Since the advent of highly active anti-retroviral therapy (HAART), the average life expectancy for HIV positive individuals has increased, and patients with HIV are experiencing lower rates of AIDS and AIDS-defining illnesses. However, as the mortality directly associated with HIV/AIDS has decreased, mortality rates from non-HIV-related conditions such as cardiac disease and non-AIDS-related cancers have increased [1]. While rates of breast, colon, and prostate cancers are similar in HIV positive and HIV negative individuals, rates of dyslipidemia and diabetes are higher among HIV positive patients [1]. Additionally, many HAART drugs such as protease inhibitors, are associated with increased risk for certain comorbid conditions such as cardiovascular disease and diabetes [2,3]. As the HIV positive population ages, it is important that clinicians provide routine, preventive health care and screening for conditions such as colon cancer, hypertension, and dyslipidemia to these patients $[1,4]$.

In 2009, the HIV Medicine Association (HIVMA) of the Infectious Diseases Society of America (IDSA) announced new guidelines for providing preventive healthcare for HIV positive individuals [5]. In accordance with the United States Preventive Services Task Force (USPSTF), the HIVMA recommends that all HIV positive individuals age 50 and older have routine colorectal and breast cancer screening [6,7]. In addition, STI testing is recommended annually for syphilis, gonorrhea and chlamydia [6]. Regular patient counseling is recommended regarding sexual behavior and drug use as well as education about healthy diet, weight reduction, smoking cessation, and seat belt use. Lastly, many vaccinations are recommended for HIV positive individuals, including inactivated annual influenza vaccine [6].

HIV positive women have unique preventive health care needs, including breast, colorectal, and cervical cancer screening, counseling about family planning and contraceptive use, and pregnancy care, as applicable [4]. USPSTF and HIVMA guidelines include annual breast and colorectal cancer screeing for women age 50 and older and cervical cancer screening starting at age 21, conducted annually if two normal Pap tests are documented during the first year after HIV diagnosis [6] and the CD4 count is $>200$ cells $/ \mu \mathrm{L}$ and increasing to every 6 months if the CD4 count is $<200$ cells $/ \mu \mathrm{L}$ [8]. Attention to preventive health care in this population is critical, as evidence suggests that they may be less likely to receive breast cancer screening then their HIV negative peers, [9] are at greater risk for sexually transmitted infections (STI), [10] and are more likely to be infected with human papillomavirus (HPV) and to develop persistent HPV infections [11]. It has been estimated that as many as $60 \%$ of HIV positive women experience co-infection with HPV [12]. HIV positive women are at increased risk for cervical dysplasia, [13] and more severe cervical cancer when compared to the general population, with a lower average age at infection and a considerably shorter developmental period [14]. HIV positive women are also at higher risk for other comorbidities such as coronary heart disease and metabolic syndrome, [15] diabetes and insulin resistance, [16] and other cancers [17]. The high burden of comorbidities among HIV positive women requires appropriate and timely preventive health care.

Unfortunately, many factors serve as barriers to care for HIV positive women, including socioeconomic and structural barriers, poverty, cultural inequities, sexual violence, physiologic differences, lack of awareness of HIV status, and the ongoing stigma of being HIV positive [18]. HIV positive women are at increased risk for social/emotional issues, [19] sexual violence, [20] trauma, substance abuse and addiction, [19] homelessness, and abuse [21]. Over half of HIV positive women report experiencing some form of intimate partner violence in adulthood [20]. In addition, HIV positive women report poorer mental health than HIV negative women, [22] and HIV positive women with depressive symptoms are more likely to report frequent and severe abuse [23]. HIV positive women who are racial/ethnic minorities are at especially high risk for disparities in health care access and quality, exacerbated by language and cultural barriers $[18,24,25]$. Non-English speaking women are less likely to receive preventive services, [26] and although professional interpreters improve the quality of care for such patients, the use of interpreters in clinical settings is vastly underutilized [27-29]. Effective patient-provider communication is key to improving quality of care, [30] including provision of recommended preventive services, but can be a challenge. Barriers to effective patient-provider communication among women with HIV, particularly racial/ ethnic minorities, may impact the quality of the preventive healthcare services they receive [31,32].

Despite improved accessibility to antiretroviral treatments, and improved life expectancy among HIV positive women in care, little research has been done to document the extent to which such women are receiving appropriate preventive health care in accordance with recommended guidelines. In this study, we conducted a medical records review of all HIV positive women seen in a Utah HIV/AIDS specialty clinic to describe the demographic characteristics of these women, identify gaps in the services they received, and evaluate predictors of receipt of preventive health services. This review was done in 2009 to correspond with the 2009 HIVMA/ IDSA guidelines for preventive healthcare for individuals with HIV/AIDS. 


\section{Methods}

\section{Data collection \& participants}

This retrospective cohort study utilized medical record reviews of HIV positive women who were patients at the University of Utah Infectious Diseases Clinic (Clinic 1A) in 2009. It is estimated that Clinic $1 \mathrm{~A}$ serves an estimated $70-80 \%$ of all HIV/AIDS patients in care in Utah. Female patients comprised $16 \%$ of the clinic population in 2009 and 13\% of individuals with HIV/ AIDS in Utah [33]. Women seen in this clinic were similar demographically to all HIV/AIDS patients in Utah. All HIV positive women seen at least once at Clinic 1A between January 1, 2009 and December 31, 2009 $(\mathrm{n}=192)$ were included in the study. Data abstractors used a standardized data collection form and entered data using protocols developed through a consensus process. Both electronic and paper medical records were reviewed for specific information about patient demographics and health screenings (blood pressure, lipid panel, cervical cancer screening, breast cancer screening, colorectal cancer screening, mental health screening, and substance abuse screening). Mammography and colorectal cancer screening were indicated for women ages 50-75 $(\mathrm{N}=40)$ in accordance with USPSTF guidelines. Medical records were also reviewed for documentation of safe sex counseling, vaccinations, sexually transmitted infection (STI) testing, and tuberculosis (TB) testing. Complete STI testing was defined as receipt of syphilis, gonorrhea, and chlamydia screening. Housing status, obtained from the medical record, was defined as stable, homeless, transient or subsidized. Lastly, the records were reviewed for comorbidities listed in the patient's "problem list", medications used, adherence (missed visits, missed doses of HAART), and referrals for eye exams, dental exams, and case management. The study was approved by the University of Utah Institutional Review Board.

\section{Statistical analysis}

Data were transferred into Stata 12.1 (College Station, Texas) for data analysis. Descriptive statistics were calculated to describe the demographic characteristics of the women (Table 1) and the preventive health services they received, with a focus on breast, cervical and colorectal cancer screening; mental health and substance abuse (including alcohol and drugs) screening; eye and dental exam referral; STI testing including syphilis, gonorrhea, and chlamydia; safe sex counseling; annual influenza vaccination; and tuberculosis (TB) testing. For bivariate analyses and multivariate regressions, we created dichotomous variables for each of the preventive health services in Table 2 (services not received/not recorded vs. service received). Because we were rarely able to determine from the medical record when a service was offered and declined (or not indicated) vs. not
Table 1 Demographics of HIV positive women seen at Clinic $1 \mathrm{~A}$ in 2009

\begin{tabular}{|c|c|c|}
\hline $\mathrm{N}=192$ & $\mathbf{N}$ & $\%$ \\
\hline \multicolumn{3}{|l|}{ Current age $^{1}$} \\
\hline $18-29$ & 25 & 13.0 \\
\hline $30-39$ & 72 & 37.5 \\
\hline $40-49$ & 52 & 27.1 \\
\hline $50-59$ & 32 & 16.7 \\
\hline$\geq 60$ & 9 & 4.7 \\
\hline \multicolumn{3}{|l|}{ Race $^{2}$} \\
\hline Caucasian & 131 & 68.2 \\
\hline African & 46 & 24.0 \\
\hline Other & 11 & 5.7 \\
\hline \multicolumn{3}{|l|}{ Ethnicity $^{3}$} \\
\hline Hispanic & 41 & 21.3 \\
\hline Non-Hispanic & 145 & 75.5 \\
\hline \multicolumn{3}{|l|}{ Insurance status ${ }^{4}$} \\
\hline Private insurance & 61 & 31.8 \\
\hline Medicaid/Medicare & 59 & 30.7 \\
\hline Primary Care Alliance (Ryan White Part C Program) & 61 & 31.8 \\
\hline Other & 10 & 5.2 \\
\hline \multicolumn{3}{|l|}{ Immigrant status ${ }^{5}$} \\
\hline US citizen & 118 & 61.5 \\
\hline Other & 47 & 24.5 \\
\hline \multicolumn{3}{|l|}{ Primary language $^{6}$} \\
\hline English & 121 & 63.0 \\
\hline Spanish & 24 & 12.5 \\
\hline Other & 42 & 21.9 \\
\hline \multicolumn{3}{|l|}{ Housing status $^{7}$} \\
\hline Stable & 137 & 71.3 \\
\hline Homeless/transient/subsidized & 38 & 19.8 \\
\hline \multicolumn{3}{|l|}{ HIV/AIDS status ${ }^{8}$} \\
\hline HIV, not AIDS & 100 & 52.1 \\
\hline AIDS & 88 & 45.8 \\
\hline
\end{tabular}

${ }^{1}$ Current age not recorded/missing for $\mathrm{N}=2$.

${ }^{2}$ Race not recorded/missing for $\mathrm{N}=4$.

${ }^{3}$ Ethnicity not recorded/missing for $\mathrm{N}=6$.

${ }^{4}$ Insurance status not recorded/missing for $\mathrm{N}=1$.

${ }^{5}$ Immigrant status not recorded/missing for $\mathrm{N}=27$.

${ }^{6}$ Primary language not recorded/missing for $\mathrm{N}=5$.

${ }^{7}$ Housing status not recorded/missing for $\mathrm{N}=17$.

${ }^{8} \mathrm{HIV} /$ AIDS Status not recorded/missing for $\mathrm{N}=4$.

offered, we combined these responses with the exception of screenings indicated by age. For screenings indicated by age, we limited analyses to women in the appropriate age ranges. We used bivariate analyses to identify differences in the receipt of preventive health services, including: cervical cancer screening, mammography, STI testing, safe sex counseling, influenza vaccination, TB testing, mental 
Table 2 Receipt of preventive services among HIV positive women seen at Clinic 1A in $2009^{1}$

Cervical cancer screening ${ }^{2}$
Yes
No
Not indicated ${ }^{4}$
Not recorded/missing
Mammogram among women age $50-75(\mathbf{N}=\mathbf{4 0})^{3}$
Yes
No
Not indicated ${ }^{4}$
Not recorded/missing

Colorectal cancer screening among women age 50-75 $(\mathrm{N}=40)^{3}$

Yes

No

Not indicated ${ }^{4}$

Not recorded/missing

Mental health screening

Yes

No

Not indicated ${ }^{4}$

Not recorded/missing

Substance abuse screening

Yes

No

Not indicated ${ }^{4}$

Not recorded/missing

Eye exam referral

Yes

No

Not indicated ${ }^{4}$

Not recorded/missing

Dental exam referral

Yes

No

Not indicated ${ }^{4}$

Not recorded/missing

Syphilis testing

Yes

No

Not indicated ${ }^{4}$

Not recorded/missing

Gonorrhea testing

Yes

No

N $\%$

$109 \quad 568$

$18 \quad 9.4$

$5 \quad 2.6$

$60 \quad 31.2$

$26 \quad 65.0$

$2 \quad 5.0$

$0 \quad 0$

$12 \quad 30.0$

$4 \quad 10.0$

$3 \quad 7.5$

$1 \quad 2.5$

$32 \quad 80.0$

159

$$
0
$$

(3)

$176 \quad 91.7$

$0 \quad 0$

$0 \quad 0$

$16 \quad 8.3$

$49 \quad 25.5$

$0 \quad 0$

$0 \quad 0$

$143 \quad 74.5$

$62 \quad 32.3$

00

$0 \quad 0$

$130 \quad 67.7$

$133 \quad 69.3$

$0 \quad 0$

$0 \quad 0$

$\begin{array}{ll}59 & 30.7\end{array}$

$86 \quad 44.8$

$0 \quad 0$
Table 2 Receipt of preventive services among HIV positive women seen at Clinic $1 \mathrm{~A}$ in $2009^{1}$ (Continued)

\begin{tabular}{|c|c|c|}
\hline Not indicated ${ }^{4}$ & 0 & 0 \\
\hline Not recorded/missing & 106 & 55.2 \\
\hline \multicolumn{3}{|l|}{ Chlamydia testing } \\
\hline Yes & 89 & 46.3 \\
\hline No & 0 & 0 \\
\hline Not indicated ${ }^{4}$ & 0 & 0 \\
\hline Not recorded/missing & 103 & 53.7 \\
\hline
\end{tabular}

Tested for syphilis, gonorrhea, \& chlamydia

Yes

$71 \quad 37.0$

No

$121 \quad 63.0$

Safe sex counseling

Yes

$65 \quad 33.9$

No

Not indicated ${ }^{4}$

Not recorded/missing

$0 \quad 0$

$3 \quad 1.6$

Annual influenza vaccine

$124 \quad 64.6$

Yes

$138 \quad 71.9$

No

Not indicated ${ }^{4}$

Not recorded/missing

$8 \quad 4.1$

B testing

Yes

$21-63.0$

No

Not indicated ${ }^{4}$

$4 \quad 2.1$

Not recorded/missing

$26 \quad 13.5$ variables for each of the preventive health services in Table 2 (services not received/not recorded/missing vs. service received).

${ }^{2} \mathrm{No}$ age cut off for women who are immunocompromised (including HIV positive) according to USPSTF recommendations.

${ }^{3}$ Excludes $\mathrm{N}=152$ participants who were outside of the USPSTF recommended age range for mammogram and colorectal cancer screening $(<50$ years or $>75$ years).

${ }^{4}$ Not indicated means the medical record has a note about a procedure not being done and why it was not done.

health screening, and substance abuse screening. Each preventive health service was evaluated by: race, Hispanic ethnicity, U.S. citizenship, housing status, insurance status, and language. Chi-squared statistics were used to evaluate the differences in screening behaviors by select demographic characteristics including race (White vs. NonWhite), ethnicity (Hispanic vs. Non-Hispanic), citizenship (U.S. citizen vs. other), housing status (stable vs. other), insurance status (private vs. other), and language (English vs. other). Finally, multivariable-adjusted odds ratios were calculated for preventive health service variables with significant between-group differences in more than one chisquared analysis. These included STI testing and safe sex counseling. Covariates of interest in these models included 
race, ethnicity, immigration status, housing status, insurance, and language. All statistical tests were two sided, and an alpha level of 0.05 was used to determine statistical significance.

\section{Results \\ Demographics}

Table 1 displays select demographic characteristics of the participants. There were 192 HIV positive women seen in Clinic 1A in 2009. Of these, $52.1 \%$ had HIV and $45.8 \%$ had AIDS. Similar to the demographics of all HIV/AIDS patients in Utah, the majority of women in the study were Caucasian $(68.2 \%)$ or of African descent (24\%). Over three quarters of women $(75.5 \%)$ were nonHispanic and $61.5 \%$ were U.S. citizens. Countries of origin included: Angola, Burma, Burundi, Congo, Ethiopia, Ghana, Liberia, Rwanda, Sudan, South Africa, Tanzania, Togo, Mexico, Argentina, El Salvador, Haiti, Honduras, Venezuela Thailand, and Russia. Sixty-six (34.4\%) women reported a primary language other than English. Languages included: Spanish, Bassa, Amharic, Arabic, Gromo, Burmese, Ewe, French, Hatian, Italian, Kingarwanda, Swahili, Linggla, Kirundi, Mali, Mende, Vai, Pakistani, Portugese, Russian, Thai, Vietnamese, and Zulu. The women had a variety of contextual and behavioral risk factors, with only $31.8 \%$ reporting private health insurance, $19.8 \%$ reporting being homeless or living in transient or subsidized housing, $38.5 \%$ having a mental health issue and $21 \%$ reporting substance abuse including abuse of alcohol or drugs.

\section{Receipt of preventive health services}

The most commonly recorded preventive health services received by HIV positive women included blood pressure screening, screening for Hepatitis A and B, TetanusDiphtheria-Pertussis vaccination, Pneumococcal pneumonia vaccination, substance abuse screening, and mental health screening. All of these preventive health services were received by at least $75 \%$ of women (data not shown). However, only $37 \%$ of women received complete STI testing including syphilis, gonorrhea, and chlamydia testing, and $33.9 \%$ had safe sex counseling documented in their medical record during the last year. Additionally, $56.8 \%$ of women received cervical cancer screening, 65\% ( $\mathrm{N}=26 / 40)$ of women age 50 or older received a mammogram and $10 \%(\mathrm{~N}=4 / 40)$ of women age 50 or older received colorectal cancer screening. Less than one-third of women received a referral for a dental or eye exam. Data on select preventive health services are shown in Table 2.

\section{Factors related to receipt of preventive health services}

Non-white women were significantly more likely to have STI testing $(\mathrm{p}=0.008)$ and safe sex counseling $(\mathrm{p}=0.001)$ documented in their medical records, while Hispanic women, English speaking women, and those with U.S. citizenship were less likely to have documented safe sex counseling ( $\mathrm{p}=0.002,0.017$, and 0.004 , respectively). Women with private insurance were also less likely to have documented STI testing $(\mathrm{p}<0.001)$ or cervical cancer screening $(\mathrm{p}=0.025)$. However, women in stable housing situations were more likely to have mental health screening $(\mathrm{p}=0.020)$, and substance abuse screening $(\mathrm{p}=0.026)$ documented in their medical records (Table 3). No significant differences in services were observed for women with substance abuse issues, comorbidities, or mental health issues (data not shown).

In order to further understand the relationship between Hispanic ethnicity, primary language, U.S. citizenship, and receipt of safe sex counseling, additional analyses were done (data not shown). Among English speakers, there were no differences in the proportion of women who had documented safe sex counseling between Hispanics and non-Hispanics. Among non-English speakers, Hispanics were much less likely than non-Hispanics to have safe sex counseling documented ( $12 \%$ vs. $65.9 \%$, p < 0.001). A similar pattern was observed when stratified by U.S. citizenship. Among U.S. citizens, there were no significant differences between the proportion of Hispanics and non-Hispanics with documented safe sex counseling. Among noncitizens, Hispanics were much less likely than nonHispanics to have safe sex counseling documented $(8.3 \%$ vs. $68.6 \%, \mathrm{p}<0.001)$.

\section{Multivariable logistic regression models for receipt of STI testing and safe sex counseling}

Documented receipt of all three recommended STI tests (syphilis, chlamydia, and gonorrhea) and documented receipt of safe sex counseling was related to a number of demographic factors among this patient population. Results of multivariable logistic regression models identifying factors that may be independently related to receipt of these services are shown in Table 4. We found that having private insurance significantly decreased a patient's likelihood of documented receipt of all three STI tests in a multivariable logistic regression model that included race, Hispanic ethnicity, immigration status, housing status, health insurance status and language (OR: 0.20; 95\% CI: 0.08 - 0.52). Women of Hispanic ethnicity were less likely to have documented receipt of safe sex counseling in a multi-variable logistic regression model that include race, immigration status, housing status, insurance status and language (OR: 0.26; 95\% CI: $0.07-0.94)$.

\section{Discussion}

Little is known about the provision of preventive health services to HIV positive women receiving care in an HIV/AIDS specialty clinic, despite evidence that such 
Table 3 Receipt of select preventive health care services, stratified by demographic characteristics ${ }^{1}$

\begin{tabular}{|c|c|c|c|c|c|c|c|c|c|c|c|c|c|c|c|c|}
\hline & \multirow{2}{*}{\multicolumn{2}{|c|}{$\begin{array}{c}\begin{array}{c}\text { Pap } \\
\text { testing }\end{array} \\
p= \\
\end{array}$}} & \multirow{2}{*}{\multicolumn{2}{|c|}{$\begin{array}{c}\text { Mammogram } \\
p=\end{array}$}} & \multirow{2}{*}{\multicolumn{2}{|c|}{$\begin{array}{c}\begin{array}{c}\text { STI } \\
\text { testing }^{2}\end{array} \\
p= \\
\end{array}$}} & \multirow{2}{*}{\multicolumn{2}{|c|}{$\begin{array}{c}\begin{array}{c}\text { Safe sex } \\
\text { counseling }\end{array} \\
p= \\
\end{array}$}} & \multirow{2}{*}{\multicolumn{2}{|c|}{$\begin{array}{c}\begin{array}{c}\text { Influenza } \\
\text { vaccine }\end{array} \\
p=\end{array}$}} & \multirow{2}{*}{\multicolumn{2}{|c|}{$\begin{array}{c}\begin{array}{c}\mathrm{TB} \\
\text { testing }\end{array} \\
\mathrm{p}= \\
\end{array}$}} & \multirow{2}{*}{\multicolumn{2}{|c|}{$\begin{array}{c}\begin{array}{c}\text { Mental health } \\
\text { screening }\end{array} \\
\mathrm{p}=\end{array}$}} & \multirow{2}{*}{\multicolumn{2}{|c|}{$\begin{array}{c}\begin{array}{c}\text { Substance } \\
\text { abuse }\end{array} \\
p= \\
\end{array}$}} \\
\hline & & & & & & & & & & & & & & & & \\
\hline & $\mathbf{N}$ & $\%$ & $\mathbf{N}$ & $\%$ & $\mathrm{~N}$ & $\%$ & $\mathbf{N}$ & $\%$ & $\mathbf{N}$ & $\%$ & $\mathrm{~N}$ & $\%$ & $\mathbf{N}$ & $\%$ & $\mathbf{N}$ & $\%$ \\
\hline Race & \multicolumn{2}{|c|}{0.682} & \multicolumn{2}{|c|}{0.979} & \multicolumn{2}{|c|}{0.008} & \multicolumn{2}{|c|}{0.001} & \multicolumn{2}{|c|}{0.225} & \multicolumn{2}{|c|}{0.182} & \multicolumn{2}{|c|}{0.472} & \multicolumn{2}{|c|}{0.151} \\
\hline White & 73 & 57.5 & 17 & 42.5 & 40 & 30.5 & 33 & 25.6 & 95 & 96.0 & 82 & 70.7 & 107 & 81.7 & 123 & 93.9 \\
\hline Non-white & 34 & 60.7 & 9 & 42.9 & 29 & 50.9 & 31 & 55.4 & 40 & 90.9 & 38 & 80.9 & 49 & 86.0 & 50 & 87.7 \\
\hline Ethnicity & \multicolumn{2}{|c|}{0.358} & \multicolumn{2}{|c|}{0.241} & \multicolumn{2}{|c|}{0.772} & \multicolumn{2}{|c|}{0.002} & \multicolumn{2}{|c|}{0.149} & \multicolumn{2}{|c|}{0.769} & \multicolumn{2}{|c|}{0.580} & \multicolumn{2}{|c|}{0.080} \\
\hline Hispanic & 21 & 51.2 & 7 & 58.3 & 16 & 39.0 & 6 & 14.6 & 27 & 90.0 & 25 & 75.8 & 33 & 80.5 & 35 & 85.4 \\
\hline Non-Hispanic & 83 & 59.3 & 19 & 39.6 & 53 & 36.6 & 57 & 40.1 & 108 & 96.4 & 93 & 73.2 & 122 & 84.1 & 136 & 93.8 \\
\hline $\begin{array}{l}\text { Immigration } \\
\text { status }\end{array}$ & \multicolumn{2}{|c|}{0.100} & \multicolumn{2}{|c|}{0.171} & \multicolumn{2}{|c|}{0.078} & \multicolumn{2}{|c|}{0.004} & \multicolumn{2}{|c|}{0.122} & \multicolumn{2}{|c|}{0.683} & & & & \\
\hline Citizen & 61 & 54.0 & 13 & 36.1 & 38 & 32.2 & 35 & 30.2 & 82 & 96.5 & 78 & 73.6 & 96 & 81.4 & 111 & 94.1 \\
\hline All other & 32 & 68.1 & 11 & 55.0 & 22 & 46.8 & 25 & 54.3 & 34 & 89.5 & 30 & 76.9 & 43 & 91.5 & 43 & 91.5 \\
\hline Housing status & & & & & & 675 & & & & & & & & & & \\
\hline Stable & 81 & 60.9 & 20 & 47.6 & 15 & 39.5 & 53 & 39.0 & 104 & 92.9 & 87 & 73.7 & 119 & 86.9 & 130 & 94.9 \\
\hline All other & 21 & 56.7 & 5 & 29.4 & 49 & 35.8 & 9 & 25.0 & 21 & 100.0 & 22 & 68.7 & 27 & 71.0 & 32 & 84.2 \\
\hline Insurance & & 25 & & & & 001 & & & & & & & & & & \\
\hline Private & 27 & 46.5 & 13 & 48.1 & 10 & 16.4 & 25 & 41.0 & 44 & 93.6 & 36 & 67.9 & 52 & 85.2 & 57 & 93.4 \\
\hline All other & 82 & 64.1 & 13 & 38.2 & 61 & 46.9 & 40 & 31.5 & 94 & 95.0 & 85 & 75.9 & 107 & 82.3 & 119 & 91.5 \\
\hline Language & & 65 & & & & 47 & & & & & & & & & & \\
\hline English & 67 & 57.8 & 17 & 44.7 & 39 & 32.2 & 34 & 28.6 & 86 & 95.6 & 80 & 74.1 & 96 & 79.3 & 114 & 94.2 \\
\hline All other & 41 & 62.1 & 9 & 40.9 & 31 & 47.0 & 30 & 46.1 & 50 & 92.6 & 39 & 70.9 & 59 & 89.4 & 58 & 87.9 \\
\hline
\end{tabular}

${ }^{1}$ Bold indicates significant at alpha level of 0.05 .

${ }^{2}$ STI testing included receipt of syphilis, chlamydia, and gonorrhea testing vs. did not receive $\geq 1$ of these tests.

Table 4 Adjusted multivariable logistic regression models for receipt of STI testing and safe sex counseling ${ }^{1}$

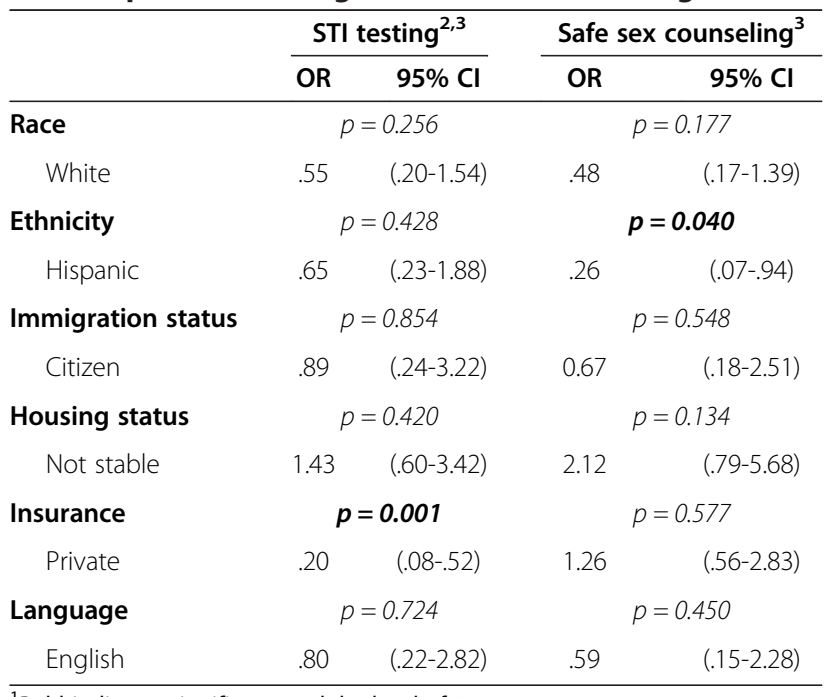

${ }^{1}$ Bold indicates significant at alpha level of 0.05 .

${ }^{2}$ STI testing included received syphilis, chlamydia, and gonorrhea testing vs. did not receive $\geq 1$ of these tests.

${ }^{3}$ Adjusted for race, Hispanic, immigration status, housing status, insurance, and language. women may suffer disparities in conditions such as heart disease, diabetes, HPV infection, and some types of cancer $[11,12,14-17]$. This study is among the first to evaluate factors associated with receipt of preventive care among such women. We found that among all HIV positive women seen for HIV/AIDS care in 2009 in an academic specialty clinic, there were wide variations in the types of services they received. Notably, STI testing and safe sex counseling were documented in the medical records of only $37 \%$ and $33.9 \%$ of women, respectively. Documentation of cancer screening was also low, with $56.8 \%$ of women having documentation of cervical cancer screening, $65 \%$ having documentation of mammography where indicated, and only $10 \%$ having documentation of colorectal cancer screening where indicated. In contrast, in Utah in 2010, 71.8\% of women age 50 and older received a mammogram, [34] 74\% received cervical cancer screening, [35] and $66.3 \%$ received colorectal cancer screening [36]. Of note, nearly a third of patients in this study (31.8\%) were covered solely through the Prevention Care Alliance (Ryan White Part C Program). Due to limited resources, such patients are not routinely referred for 
services such as dental or eye exams or colonoscopy. The majority of these patients do not have funds to cover the out of pocket expenses associated with these services.

In the context of the preventive health services received by this patient population, it is important to point out that these patients are clinically challenging for several reasons. More than one-third of the HIV positive women in this study spoke a language other than English, nearly 1 in 5 did not have stable housing arrangements, and there were high rates of mental health issues and substance abuse among them. These issues make it challenging for clinicians to provide a full range of preventive services during busy HIV/AIDS-related clinic visits, as many these women have multiple issues that need to be addressed in addition to their HIV/AIDS care. However, these challenges are likely true for any healthcare provider caring for HIV positive women and are not unique to HIV positive women in Utah.

Interestingly, we found that racial minorities and nonEnglish speakers were more likely to receive some types of preventive services than Caucasian or Englishspeaking women. For example, we found that White women, U.S. citizens, and English-speakers were less likely to have safe sex counseling documented. White women and those with private health insurance were less likely to have STI testing documented. Women with private insurance were also less likely to have cervical cancer screening documented. In multivariable models, women with private health insurance were less likely to have documented STI testing. These findings may be due to several issues including the practices of specific providers who tend to care for different types of patients (English vs. Spanish-speaking patients, for example). In addition, the out-of-pocket expenses associated with some of these services may require co-payments for privately insured patients, but may be available at no cost to publically insured patients. Finally, privately insured patients may have primary health care providers outside of the University of Utah system and may not have preventive services received outside of the system documented in their University medical records.

This study advances prior research by incorporating data from a clinic which serves a large proportion of HIV positive women in the state of Utah. Clinic 1-A is the premier HIV-AIDS clinic in Utah, and captures the majority of HIV positive women in the state. A thorough chart audit process was used, including searching for lab values (i.e. cervical cancer screening results) if they were not included in the patient's medical record. This process provided accurate data about the provision of preventive health services to all patients seen in the clinic in 2009. As the HIVMA introduced new guidelines for preventive care of HIV positive individuals in 2009 , these data can be used in future studies to explore changes in providers' recommendation and provision of preventive services for this population.

There are several important limitations to the study. The study clinic is not part of a closed health care system, and it is possible that some patients may have had primary care providers outside of the University of Utah system. We were unable to query those records. In many cases, the provision of clinical services was not documented at all. In these instances, we assumed that the services were not provided. This may be an inaccurate assumption, for example, in the case of safe-sex counseling, which may be done conversationally but not recorded in the medical record. We did not collect detailed information on contraceptive methods (e.g., tubal, hormonal etc.) as many women received these from other sources $(\mathrm{OB} /$ GYNs, family planning clinics). Investigating the provision of contraceptives to HIV positive women is an important future research opportunity.

Lastly, at the time of this study, the clinic was using primarily paper-based medical records, with some labs and other results available electronically. Since that time, the clinic has switched to exclusively electronic charting. In the future, we hope to compare data on the provision of preventive health services under the new electronic medical record system to see if utilization of such a system has helped improve reporting of the proportion of women receiving recommended services.

When reviewed in the context of the HIVMA/IDSA guidelines for the preventive care of HIV positive women, patients in this study were less likely to have received mammography, cervical cancer screening, or colonoscopy then women in the general Utah population. Receipt of colorectal cancer screening was notable low, with only 1 in 10 patients receiving such screening. Receipt of STI testing and safe sex counseling were also very low, with documentation in the medical records of $37 \%$ and $33.9 \%$ of patients, respectively. However, on a positive note, rates of substance abuse screening were high (91.7\%) and nearly three quarters of women (71.9\%) received an annual influenza vaccine.

\section{Conclusions}

In 2009, the HIV Medicine Association (HIVMA) of the Infectious Diseases Society of America (IDSA) recommended HIV positive women receive routine, preventive health care as a part of their regular HIV/AIDS care. However, in an academic specialty HIV/AIDS clinic serving a large proportion of the HIV positive women in Utah, we found that the provision of many recommended preventive services was lacking, particularly among women with fewer socio-demographic risk factors (i.e., insured, White race, stable housing etc.). Our findings serve as a reminder that HIV/AIDS providers must focus on the needs of all women for preventive 
care services, not only those who may be perceived to be part of a vulnerable population. In addition, failure to provide preventive services such as STI testing, cancer screening, or safe sex counseling to all patients represents a missed opportunity for provision of services that are important from both a clinical and public health perspective. Finally, given the longevity of HIV positive patients in the era of HAART and the extensive list of recommended preventive health care services, the optimal setting for the care of such patients may need to shift away from infectious diseases specialty clinics towards general medicine clinics with HIV/AIDS consultants. As HIV/AIDS continues to evolve as a disease, new health care models may be needed to address the complex needs of patients including preventive health care, mental health and substance abuse services, and social services in addition to HIV/AIDS care.

\section{Consent}

As this was a medical record review and no patients were contacted, informed consent was waived by the University of Utah Institutional Review Board.

\begin{abstract}
Abbreviations
HAART: Highly Active Anti-Retroviral Therapy; HIVMA: HIV Medicine Association; IDSA: Infectious Diseases Society of America; USPSTF: United States Preventive Services Task Force; HIV: Human Immunodeficiency Virus; AIDS: Acquired Immune Deficiency Syndrome; STI: Sexually Transmitted Infection; Pap: Papanicolaou test; HPV: Human Papillomavirus;

TB: Tuberculosis; Clinic 1A: University of Utah Infectious Diseases Clinic.
\end{abstract}

\section{Competing interests}

The authors declare that they have no competing interests.

\section{Authors' contributions}

SES designed the study, assisted with the chart reviews, assisted with the data analysis, and drafted the manuscript. DK and EW performed data analysis and drafted the manuscript. JT, MS, and KR provided input into the study design, assisted with the chart reviews, and provided critical feedback on manuscript drafts. All authors read and approved the final manuscript.

\section{Acknowledgements}

The authors would like to acknowledge Hina Yazdani, MPH and Meredith White, CSW, LISW-S for their assistance conducting chart reviews for this project. The authors would also like to acknowledge Tiffani Pestotnik and Harry Rosado, MD for their thoughtful review of drafts of this manuscript. This project was completed with funding by the Utah AIDS Education and Training Center.

\footnotetext{
Author details

'Department of Family and Preventive Medicine, Division of Public Health, University of Utah, 375 Chipeta Way, Suite A, Salt Lake City, UT 84108, USA. ${ }^{2}$ College of Nursing, University of Utah, Huntsman Cancer Institute; 2000 Circle of Hope, Salt Lake City, UT 84112, USA. ${ }^{3}$ Department of Internal Medicine, Division of Infectious Diseases, University of Utah, 30 North 1900 East, Room 4B319, Salt Lake City, UT 84112, USA. ${ }^{4}$ Cancer Control and Population Sciences, Huntsman Cancer Institute; 2000 Circle of Hope, Salt Lake City, UT 84112, USA.
}

Received: 19 November 2013 Accepted: 26 February 2014 Published: 4 March 2014

\section{References}

1. Sheth AN, Moore RD, Gebo KA: Provision of general and HIV-specific health maintenance in middle aged and older patients in an urban HIV clinic. AIDS Patient Care STDS 2006, 20(5):318-325.

2. Rhew D, Bernal M, Aguilar D, lloeje U, Goetz M: Association between protease inhibitor Use and increased cardiovascular risk in patients infected with human immunodeficiency virus: a systematic review. Clin Infect Dis 2003, 37(7):959-972.

3. Justman JE, Benning L, Danoff A, Minkoff H, Levine A, Greenblatt RM, Weber K, Piessense E, Robinson E, Anastos K: Protease inhibitor use and the incidence of diabetes mellitus in a large cohort of HIV-infected women. J Acquir Immune Defic Syndr 2003, 32(3):298-302.

4. Tello MA, Yeh HC, Keller JM, Beach MC, Anderson JR, Moore RD: HIV women's health: a study of gynecological healthcare service utilization in a U.S. urban clinic population. J Womens Health (Larchmt) 2008, 17(10):1609-1614.

5. Primary care key to management of patients with HIV infection. [http:// www.idsociety.org/2013_HIV_Guidelines/]

6. Aberg JA, Kaplan JE, Libman H, Emmanuel P, Anderson JR, Stone VE, Oleske JM, Currier JS, Gallant JE: Primary care guidelines for the management of persons infected with human immunodeficiency virus: 2009 update by the HIV medicine Association of the Infectious Diseases Society of America. Clin Infect Dis 2009, 49(5):651-681.

7. Recommendations for adults. [http://www.uspreventiveservicestaskforce. org/adultrec.htm]

8. Cancer screening. [http://www.hiv.va.gov/provider/manual-primary-care/ cancer-screening.asp\#S3X]

9. Momplaisir F, Mounzer K, Long JA: Preventive cancer screening practices in HIV-positive patients. AIDS Care 2013, 26(1):87-94.

10. McGowan JP, Shah SS, Ganea CE, Blum S, Ernst JA, Irwin KL, Olivo N, Weidle PJ: Risk behavior for transmission of human immunodeficiency virus (HIV) among HIV-seropositive individuals in an urban setting. Clin Infect Dis 2004, 38(1):122-127.

11. Strickler HD, Burk RD, Fazzari M, Anastos K, Minkoff H, Massad LS, Hall C, Bacon M, Levine AM, Watts DH, Silberberg MJ, Xue X, Schlecht NF, Melnick S, Palefsky JM: Natural history and possible reactivation of human papillomavirus in human immunodeficiency virus-positive women. J Natl Cancer Inst 2005, 97(8):577-586.

12. Vonau B, Boag F: HIV-positive women and cervical screening. Int J STD AIDS 2000, 11(12):767-773.

13. Danso D, Lyons F, Bradbeer C: Cervical screening and management of cervical intraepithelial neoplasia in HIV-positive women. Int J STD AIDS 2006, 17(9):579-584. quiz 585-577.

14. Frisch M, Biggar RJ, Goedert JJ: Human papillomavirus-associated cancers in patients with human immunodeficiency virus infection and acquired immunodeficiency syndrome. J Natl Cancer Inst 2000, 92(18):1500-1510

15. Baum MK, Rafie C, Lai S, Xue L, Sales S, Page JB, Berkman R, Karas L, Campa A: Coronary Heart Disease (CHD) risk factors and metabolic syndrome in HIVpositive drug users in Miami. Am J Infect Dis 2006, 2(3):173-179.

16. Longenberger A, Lim JY, Orchard T, Brooks MM, Brach J, Mertz K, Kingsley LA: Self-reported low physical function is associated with diabetes mellitus and insulin resistance in HIV-positive and HIV-negative men. Futur HIV Ther 2008, 2(6):539-549.

17. Berry JM, Palefsky JM, Welton ML: Anal cancer and its precursors in HIVpositive patients: perspectives and management. Surg Oncol Clin N Am 2004, 13(2):355-373.

18. Kates J, Hoff T, Levine S, Carbaugh A, Gutierrez C: The Henry J. Kaiser Family Foundation: A Report on Women and HIV/AIDS in the US. Menlo Park, California; 2013.

19. McDonnell KA, Gielen AC, O'Campo P, Burke JG: Abuse, HIV status and health-related quality of life among a sample of HIV positive and HIV negative low income women. Qual Life Res 2005, 14(4):945-957.

20. Campbell JC, Baty ML, Ghandour RM, Stockman JK, Francisco L, Wagman J: The intersection of intimate partner violence against women and HIV/ AIDS: a review. Int J Inj Contr Saf Promot 2008, 15(4):221-231.

21. Machtinger EL, Wilson TC, Haberer JE, Weiss DS: Psychological trauma and PTSD in HIV-positive women: a meta-analysis. AIDS Behav 2012, 16(8):2091-2100.

22. Bernatsky S, Souza R, de Jong K: Mental health in HIV-positive pregnant women: results from Angola. AIDS Care 2007, 19(5):674-676. 
23. Illangasekare S, Tello M, Hutton H, Moore R, Anderson J, Baron J, Chander G: Clinical and mental health correlates and risk factors for intimate partner violence among HIV-positive women in an inner-city HIV clinic. Womens Health Issues 2012, 22(6):e563-e569.

24. Vyavaharkar MV, Moneyham L, Corwin S: Health care utilization: the experiences of rural HIV-positive African American women. J Health Care Poor Underserved 2008, 19(1):294-306.

25. Escarce JJ, Goodell S: Racial and ethnic disparities in access to and quality of health care. Synth Proj Res Synth Rep 2007(12). This is a policy brief from the Robert Wood Johnson Foundation, the URL is http://www.health.state. mn.us/divs/hpsc/hep/transform/novdocuments/rwjsynthesis.pdf.

26. Woloshin S, Schwartz LM, Katz SJ, Welch HG: Is language a barrier to the use of preventive services? J Gen Intern Med 1997, 12(8):472-477.

27. Diamond LC, Schenker Y, Curry L, Bradley EH, Fernandez A: Getting by: underuse of interpreters by resident physicians. J Gen Intern Med 2009, 24(2):256-262

28. Yawman D, Mclntosh S, Fernandez D, Auinger $P$, Allan M, Weitzman M: The use of Spanish by medical students and residents at one university hospital. Acad Med 2006, 81(5):468-473.

29. Lee KC, Winickoff JP, Kim MK, Campbell EG, Betancourt JR, Park ER, Maina AW, Weissman JS: Resident physicians' use of professional and nonprofessional interpreters: a national survey. JAMA 2006, 296(9):1050-1053.

30. Institute of Medicine: Crossing the quality chasm: a new health system for the twenty-first century. Washington; 2001. http://www.iom.edu/ Reports/2001/Crossing-the-Quality-Chasm-A-New-Health-System-for-the21st-Century.aspx.

31. Johnson RL, Saha S, Arbelaez JJ, Beach MC, Cooper LA: Racial and ethnic differences in patient perceptions of bias and cultural competence in health care. J Gen Intern Med 2004, 19(2):101-110.

32. Reyna VF, Adam MB: Fuzzy-trace theory, risk communication, and product labeling in sexually transmitted diseases. Risk Anal 2003, 23(2):325-342.

33. UTAH HIV/AIDS epidemiological profile-update-2009. [http://utah.ptfs. com/awweb/awarchive?item=30767]

34. Query Results for Utah's Behavioral Risk Factor Surveillance System (BRFSS) combined landline and cell query module. [http://ibis.health.utah. gov/query/result/brfss/LandlineCell_BRFSSCrude40/Mammo.html]

35. Important facts for cervical cancer screening. (Pap) [http://ibis.health.utah. gov/indicator/important_facts/CervCAScr.html.]

36. Important facts for colorectal cancer screening. [http://ibis.health.utah. gov/indicator/important_facts/ColCAScr.html]

doi:10.1186/1472-6874-14-37

Cite this article as: Simonsen et al:: Preventive health care among HIV positive women in a Utah HIV/AIDS clinic: a retrospective cohort study. BMC Women's Health 2014 14:37.

\section{Submit your next manuscript to BioMed Central and take full advantage of:}

- Convenient online submission

- Thorough peer review

- No space constraints or color figure charges

- Immediate publication on acceptance

- Inclusion in PubMed, CAS, Scopus and Google Scholar

- Research which is freely available for redistribution 